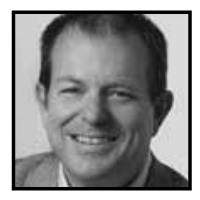

\title{
Commentary
}

\section{The Need for a Deeper Exploration and Conceptual Understanding: The Critical Role of Creativity and Collaboration in Real-World Learning}

\author{
R. Keith Sawyer
}

\section{ABSTRACT}

In this interview, author and professor R. Keith Sawyer describes the importance of and interconnections among creativity, collaboration, and the science of learning. He explains that the older paradigm of schooling from 50 years ago where rote learning was predominant is no longer relevant in a knowledge-based society. We now have to prepare students for jobs that require adaptability, flexibility, and creativity. He endorses an approach to education that fosters a deeper conceptual understanding, especially through collaborative creativity. He maintains that true innovation usually comes from a collaboration of individuals rather than a single, brilliant insight. Finally, he comments on recent findings in cognitive neuroscience.

You have written and presented extensively on creativity and the science of learning. How and why did you become interested in these areas?

became interested in creativity many, many years ago because as a child I was a pianist, and playing piano was a big part of my life. I was first trained as a classical pianist. For about eight years I played traditional European music and then I had an opportunity to join our high school jazz band. I was surprised to discover that the music put before me at the piano had no notes, it just had chord symbols and I was expected to improvise. I went through the experience of having to teach myself how to play piano all over again, and then, being fascinated with the musical 
interaction that takes place in a jazz ensemble when all of the musicians are improvising and yet they're improvising together. They're being inspired by each other to play better and more creatively than they could have alone. That fascination has stayed with me my entire career, the fascination with group creativity and group improvisation, and that's what I've focused my research on.

Can you explain why you believe creativity and collaboration are key elements of an education?

I think creativity is absolutely critical, perhaps more so today at this point in time than ever in the past. I suppose that we need to think about what school is for and what we expect of our graduates. We are in a knowledge age, it's often been said that we're in a creative age. Particularly in an advanced industrial society, the jobs that do not require creativity tend to be outsourced to low-wage countries or they are automated by advancing computer technology and robots. What people can do-and robots can't do-is creativity. And yet I feel that in many cases our school systems are in a sense still designed for an economy and a society that doesn't exist any more. The schools are very similar to what they were in the 1920s or the 1950 s when most jobs did not require so much creativity and people could engage in the same rote, repetitive behaviours and they might stay in the same job for 40 years. That world is gone, and if we continue to educate our students in the same way as 50 or 60 years ago, then we're not preparing them for the $21^{\text {st }}$ century where they will need adaptability, they will need flexibility, they will need creativity, they'll need to adapt to multiple different jobs over the course of their career. That's why I think creativity is particularly important now, more so than ever in the past.

\section{Can you discuss how you believe creativity and collaboration are linked?}

In my own research I focus on group creativity and collaborative creativity. It's a bit of a shift from a psychological perspective: when you're trained as a psychologist you're trained to focus on the individual person and the mind of a single individual. If you're thinking about creativity in that framework then you'll naturally think about what goes on in a person's mind when they're being creative or when they're having bright creative insights. When I began to study the creativity literature and then studied the history of invention, it seemed more and more clear to me that real-world creativity - the kind of creativity that actually has an impact on the world, that has a difference in our lives-is almost never the result of one person having a brilliant idea. 
I think largely that "big insight" idea is mythical, and in fact, what I found over and over again is that important creative works, or important inventions, always involve lots and lots of ideas, many of them very small ideas, and they all have to come together in a very complex way to result in a successful innovation. I see that over and over again, even inventions from the $19^{\text {th }}$ century, like the invention of the telegraph, the invention of the telephone, a little bit later, the invention of the airplane. In the contemporary era, the invention of something as simple as a new brand of guitar strings, or as complex as a new Broadway musical, a Hollywood movie, a new video game, a new computer software product-all of these things involve immense amounts of collaboration. In a Pixar movie, an animated digital movie, every single frame involves multiple ideas, there's 30 frames a second, so the idea that you can have one person having a great idea, and have that be the full explanation of creativity, I think that's ridiculous. In fact, the full explanation of creativity is always going to involve how did all these different people come together and bring together their own individual ideas, which each in a sense are very small, but when they all come together they can result in something big and powerful. And that's the role of collaboration: it's bringing people's ideas together so that they can result in something that actually will make a difference in the world.

What key things do you think educators should know about the science of learning, and why?

There is an exciting new science of learning that's grown in the past 20 years. In 1991 the Journal of the Learning Sciences was founded. There was research going on, perhaps in the 10 or 20 years before that, into the science of learning, but it began to coalesce and people who were doing this sort of research began to collaborate with each other, attend the same conferences, and exchange ideas. So we had an incredible growth starting in the 1990s, and after 20 years we know more about how people learn than we ever have in the past. I was the editor of a handbook that captured all of the research in that area. It was published in 2006 by Cambridge University Press; and that captured the previous 15 years of research in that area. It's exciting because it shows how people learn in a deeper, more profound way.

The learning sciences is not so much about how can we help students memorize more effectively so that they can regurgitate the material better on the test. Again, that is sort of an older paradigm of schooling and education: that we need to deliver a lot of information to students and have them memorize it really thoroughly and then take the test to prove that they've memorized it. Then of course 
what happens is a month after the test they've forgotten everything! I actually ask my students in my college classes ... I'm in a very good university so all of these students got straights A's in their classes ... then I say, "How many of you have the experience of getting A's on everything in a class and feeling like you really had no idea what it was really about and you really didn't understand it?" And every single one of my students will raise their hand: they get A's without understanding. Now again, it might have been fine in the 1950s or the 1960s when we were in a different era, but that's not going to cut it anymore because to be creative, to engage in adaptive expertise at a high level you need a deeper conceptual understanding of the material. You need to know what it means, you need to be able to think with the concepts; memorizing and regurgitating doesn't prepare you to be creative. The exciting thing about the learning sciences is that it has always been focused on how can we help students get to a deeper conceptual understanding, how can we help them think creatively with material. There is research out there if you want to know what the best way is to memorize stuff better, and I would certainly consider that part of the learning sciences, but the more exciting part is this new way of thinking about education. It's different now: we need to prepare students to be creative. To do that we need them to have a deeper understanding of material and the research is helping us understand how schools and teachers can do that more effectively.

\section{Can you give some suggestions of how educators can foster creativity?}

Some of the suggestions would be similar to what I said while answering the last question. The focus should be on deeper conceptual understanding and thinking abilities rather than on memorization of facts or learning how to execute a sort of rote procedure. I think you could apply this to any subject area, regardless of whether you're teaching in history class, in English literature, in mathematics or science-the principles are all the same. For example, memorizing facts, in some cases there are certain things you just need to memorize; you will learn how to multiply more effectively if you memorize the multiplication table - I would grant that absolutely. But ultimately that's a basis for what we really want, which is for people, students to understand the underlying model of what it means.

For example, in seventh grade, eighth grade mathematics class is typically a time when students are learning about fractions, decimals, and percentages. With fractions they may learn how to...they are being taught how to multiply fractions, how to divide fractions, how to find the least common denominator. The way math is taught typically is that they are taught a rigid procedure that gets them to the answer. 
Then they are given a worksheet or they do maybe 30 problems-you're multiplying fractions, 30 different fractions. And then you get a quiz and in the quiz they know what the procedure is to multiply fractions. That's exactly the opposite of what I think we need to teach students to be creative, because creativity comes from having that understanding of the underlying model, the deeper concepts that unify the idea. I've had the experience with students learning how to multiply fractions really well but if you ask them questions in a different sort of way you realize that they really don't understand what a fraction is. They can't make the connection between a fraction and a percentage, for example. They don't know that one fourth is the same thing as $25 \%$-and these are students that get A's; but they're not getting the deeper conceptual understanding. We know from creativity research that's what prepares you to be creative. It's that deeper conceptual understanding; it's having the representation of the underlying model. I would say for teachers, in all cases, try to figure out what is that deeper understanding of the material I'm trying to teach, and how can I help students develop that deeper understanding.

\section{What would you suggest to educators to help foster collaboration?}

That's a tricky question because there's all sorts of research that shows that students don't naturally know how to collaborate effectively. I think educators and education researchers for decades now have believed in the power of putting students in groups to work together, but it doesn't always work. If you have ten or eleven year-olds or twelve year-olds, they don't naturally know how to collaborate effectively for most effective learning. I think it's the responsibility of teachers to help scaffold these students in what it means to engage in an effective collaboration. It's tricky, they're ten year-olds, they're eleven year-olds, they have all sorts of things going on in their lives, they have social relationships outside of the learning environment, they may be friends, they might not be friends. It requires a lot of effort on the part of teachers. You have to emphasize that learning is a shared endeavour; that it's our joint responsibility to work toward an understanding of the material.

There's sort of broad norms we need to establish in a classroom. And then there are more specific things: the types of questions that you would hope your students would ask in a collaborative group, the types of answers they would provide. We have decades of research showing that in a collaborative group the students are asking, "What answers did you get for this question?" and the other student says, "I got 3.5." That sort of interaction is not helpful; it does not contribute very much to learning. So basically you're wasting the potential of the collaborative group. In 
contrast, when the groups are contributing more effectively to learning, it's when the students ask each other more exploratory questions, more open-ended questions ... and the answers tend to be more about concepts and models, tied into some of my answers to the previous questions. These are things that are very difficult for students to learn how to do now but teachers, I think, could be aware, or need to be aware, of this research; you're circulating among the groups, you're listening to students, and it could help if you could develop exercises for the groups which support the students and guide them gently towards asking a different sort of question of each other and engaging in a more exploratory, more conceptually based type of discussion when they're in the group. A group that is focused on getting the right answer and "What did you get?"-that's a waste of collaboration; you're not going to get any benefit from that. It has to be a deeper exploration of the fundamental material that we're trying to master in this particular activity.

Last year we had the pleasure of hearing you speak and you described an example of creativity, collaboration, and innovation about the Monopoly game invention. Could you tell us about that?

The story of how Monopoly was created is a wonderful story because we have a certain belief about how these things happen. The official story from the Parker Brothers Company, the game company, when Monopoly was released in 1934 or 1935 ... an incredible success, it was selling faster than any board game had ever sold before. Newspaper reporters actually wanted to write stories about the phenomenon, the Monopoly phenomenon ... so they were calling Parker Brothers up, "we'd like to interview the inventor of Monopoly." They put the reporters in touch with this man, Charles Darrow, who had the patent for the Monopoly game, and he told the story about how he was sitting in his basement and sort of had this flash of insight to develop this board game where people would buy and sell real estate. Well, it turns out that it was a complete lie, that in fact Charles Darrow essentially just copied a game that was being played among various communities up and down the east coast of the United States and in the mid-west primarily among Quakers, the Quaker religious community, and for about 30 years they had been making their own handmade copies of this game they called the Landlord's Game, which the first known copy of is from 1904. Each city, when you're making a copy for your own family, named all the space names on the board after neighborhoods and streets in your town. So, wherever you found a copy of this game it would be different; it would represent your own city. Charles Darrow happened to have some friends in Atlantic City, New Jersey, which is where he first encountered this game and then he copied it and fraudulently 
obtained a patent. And all the streets, by the way, on the Monopoly Game are streets from Atlantic City, New Jersey, but purely by historical accident.

The reason why I like the story is because it shows how often innovation, even though we like to think of it as the flash of insight of a solitary individual, in fact this story is representative of how it more likely happened, that it takes a long time, there are contributions from a lot of different people over this 30-year time frame. You have a lot of different variations: every city has a different version of Monopoly or the Landlord's Game, and everybody has slightly different rules. This is the nature of innovation. It's almost like a kind of evolution where it is not guided and there's no plan really but people try out new things and new ways and some of them survive, and some of them don't survive. After this 30-year process even with a successful board game but not because of one person's brilliant insight, because of the creative power of collaboration kind of stretched out over time. I call it the "collaborative web" because it represents the way that networks and relationships bring people together so that they can more effectively exchange their own creative ideas so that they'll come together and build together toward something more powerful and more effective.

You also talked about brainstorming and some of the misconceptions about brainstorming. Would you discuss that a little bit for us?

Brainstorming is a very widespread and popular technique. It tends to refer to different things. Sometimes when people say "brainstorming" they just mean, "let's get together and talk about this." But, originally brainstorming was coined by an advertising executive named Alex Osborn-I think it was way back in the 1930s, the 1940s. He had four basic principles: that you should be wild and crazy, that you should go for a large quantity of ideas, don't worry about being critical about them, don't worry about how good they are, just go for the volume and try to build off of other people's ideas. A lot of people when they do brainstorming, say it's in a business setting, that's what they'll do: they'll get together and they'll throw out ideas. The interesting thing is as long ago as the 1950s when psychologists first did an experiment on this, they find that if you take four people and put them in a brainstorming group and you count how many ideas they generate in 30 minutes, and then you take four people and have them all work alone for 30 minutes, following the same guidelines (i.e., volume and quantity) and then you pool their four lists at the end of 30 minutes: they generate way more ideas than the four people that were face to face doing brainstorming-typically twice as many ideas. That finding is sobering. I guess the implication is that if you really want a large amount of ideas, don't put people together 
in a room; let them generate their lists separately. That's the surprising finding ... it doesn't seem to work as advertised, but once you know the research then you can be more strategic about how you use brainstorming. You could have people generate lists of ideas in their own office and then bring them together and they come to the room with their list of ideas ... and then you can take advantage of the real power of collaboration to engage in what I think of is sort of an improvisational flow, a conversation where surprising new ideas can emerge. So don't use the brainstorming group simply to generate long lists of ideas-use the brainstorming group after everybody has already come up with lists of ideas and then try to take those and combine them in some way ... build on those to result in something surprisingly new that no one had thought of on their own.

Learning about the brain and how it works has become very, very popular. In fact, that's what this issue is about. Do you have any suggestions for educators about how to use this research effectively?

I recently did a review of cognitive neuroscience studies of creativity. There hadn't been such a review of the literature. An increasing number of people have been doing brain scanning where they generate three-dimensional brain images of people while they're engaged in tasks that seem to involve some creativity. It has to be a task that you can do over and over again and it has to be a task that anyone can do. So you're not asking people to compose Beethoven's 6th Symphony while they're in the brain scanner, but you're asking them to do something like, "here are three related words and try to think of a fourth word that's related to these three words."

Psychologists believe that that involves some of the same basic cognitive or mental processes that may underlie creative behavior. That's the kind of experimental paradigm you're using ... you have people engaged in these tasks which seem to involve some component of creativity but it's not really like Steve Jobs coming up with the iPhone or something like that that's going to be impossible to study in a sort of rigorous experimental way. These are the studies ... there's been an increasing number of them. The interesting thing to me is that what you find is that creativity-or these tasks that are somehow perhaps related to creativity-they're not really located in a specific brain region-they're spread out all over the brain. A lot of the brain is active when you're engaged in these sorts of creative activities or creative mental processes. In some cases, one small region of the brain might be slightly more active, or another region might be slightly more active, but it varies quite a bit and the conclusion I take from that is this: you need the entire brain working in concert to 
engage in creativity. We know pretty conclusively now that it's a complete myth that creativity is in the right brain, and we've known that before from other methodologies but it's even more convincing now that we have this brain-imaging technology available. It's absolutely not the case that these creative activities are in the right brain or that some people turn out to be more "right brained" than others. It's sort of maybe a conversational shorthand we use for certain personality types but it has no basis in brain reality.

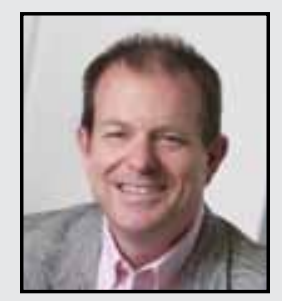

R. Keith Sawyer, a professor of psychology and education at Washington University in St. Louis, studies creativity, learning, and collaboration. He has a computer science degree from MIT as well as an M.A. and PhD in psychology from the University of Chicago. He has been a jazz pianist for over 30 years, and spent several years playing piano with Chicago improv theater groups. Dr. Sawyer has published ten books and over 60 scientific articles. A popular speaker, he lectures to corporations, associations, and universities around the world on creativity and innovation. He is a participant in the Davos World Economic Forum.

LINKTO:

http://www.keithsawyer.com/ 